\title{
PENGEMBANGAN APLIKASI ANDROID UNTUK PEMBELAJARAN PNEUMATIK
}

\author{
Anwar Setiadi ${ }^{1}$, Pitoyo Yuliatmojo, ${ }^{2}$, Diat Nurhidayat ${ }^{3}$ \\ ${ }^{1,2,3}$ Dosen Prodi Pendidikan Teknik Elektronika Fakultas Teknik Universitas Negeri Jakarta \\ Email: ${ }^{1}$ anwarsetya1@gmail.com, ${ }^{2}$ pitoyo ok@unj.ac.id, ${ }^{3}$ diat@unj.ac.id
}

\begin{abstract}
Abstrak - Penelitian ini merupakan pengembangkan aplikasi android untuk pembelajaran pneumatik dengan mengetahui tingkat kelayakannya aplikasi berdasarkan penilaian ahli materi, ahli media, praktisi pembelajaran pneumatik (guru), dan siswa. Penelitian menggunakan metode pengembangan (Research and Development) yang diadaptasi dari model pengembangan ADDIE (Analisis, Design, Development, Implementation, and Evaluation), Hasil Penelitian menunjukan bahwa tingkat kelayakan aplikasi android pembelajaran pneumatik mendapatkan penilaian berdasarkan : 1) ahli materi diperoleh rata-rata skor 4.55 yang termasuk kategori sangat layak, 2) ahli media diperoleh rata-rata skor 4.31 yang termasuk kategori sangat layak, 3) praktisi pembelajaran pneumatik (guru) diperoleh rata-rata skor 4.54 yang kategori sangat layak, dan 4) Siswa diperoleh rata-rata skor 4.03 yang termasuk kategori layak. Maka dapat disimpulkan bahwa pengembangan aplikasi android untuk pembelajaran pneumatik layak digunakan sebagai multimedia pembelajaran interaktif dalam pembelajaran pneumatik.
\end{abstract}

Kata Kunci: Bahan Ajar, Pneumatik, Multimedia Pembelajaran Interaktif, Android

Abstract - develop android application for pneumatic learning by knowing the level of feasibility based on the assessment of material experts, media experts, pneumatic learning practitioners and students. This study uses development method (Research and Development) which was adapted from the ADDIE model (Analysis, Design, Development, Implementation and Evaluation). The results shows that the level of feasibility of pneumatic teaching materials as an interactive learning multimedia based on android get an assessment based on: 1) material experts with an average score of 4.55 which falls into category of very feasible, 2) media experts with an average score of 4.31 which falls into category of very feasible, 3) pneumatic learning practitioners (teachers) with an average score of 4.54 which falls into category of very feasible, and 4) Students with an average score of 4.03 which falls into the suitable category. Therefore, it can be concluded that the development of pneumatic materials based on android is worthy to be used as an interactive learning multimedia in pneumatic learning.

Keywords: Learning materials, Pneumatic, Interactive Learning Multimedia, Android. 


\section{PENDAHULUAN}

Perkembangan ilmu pengetahuan dan teknologi semakin mendorong adanya pembaharuan dalam pemanfaatan hasil-hasil teknologi yang dapat diterapkan dalam proses pembelajaran. Sejalan dengan hal tersebut para pendidik diharuskan agar mampu menggunakan hasil teknologi tersebut yang dapat digunakan sebagai media pembelajaran dalam proses belajar mengajar, tidak menutup kemungkinan bahwa alat-alat tersebut sesuai dengan perkembangan teknologi yang semakin modern.

Smartphone adalah perangkat telepon genggam handphone yang bisa digunakan untuk berkomunikasi (mengirim pesan singkat dan telepon), serta di dalamnya terdapat fungsi PDA (Personal Digital Assistant) yang dirancang untuk membantu orang mengatur hidup mereka seperti menyimpanan data, no telepon, agenda, dll. Menurut lembaga riset Roy Morgan, pada periode 2012-2013 kepemilikan smartphone di Indonesia naik dua kali lipat, yaitu dari $12 \%$ menjadi $24 \%$ dari total populasi di Indonesia dan kepemilikan tersebut didomiasi oleh remaja, dari total kepemilikan smartphone, 89\% menggunakan smartphone mereka untuk berinteraksi dengan teman-teman, kemudin 56\% menggunakan smartphone mereka untuk berinteraksi dengan keluarga mereka, dan 35\% lainya menggunakan smartphone mereka untuk berkomunikasi dengan guru-guru mereka. Menurut lembaga riset Digital Marketing Emarketer memperkirakan jumlah pengguna aktif smartphone di Indonesia pada tahun 2018 akan menembus lebih dari 100 juta orang.

Berdasarkan hasil pengamatan dan wawancara peneliti dengan praktisi pembelajaran pneumatik yang dilakukan pada saat kegiatan pembelajaran pneumatik di SMK Negeri 4 Jakarta yaitu guru mempunyai permasalahan karena belum mempunyai media pembelajaran yang sesuai dengan standart pembelajaran yang seharusnya, yaitu belum adanya bahan ajar yang terangkum sebagai bahan belajar siswa dan belum adanya jobsheet sebagai pendukung kegiatan praktik pneumatik. Maka perlu adanya Pengembangan Bahan Ajar Pneumatik dalam bentuk aplikasi android.

\section{METODOLOGI PENELITIAN}

Penelitian dilakukan pada siswa kelas XI Jurusan Mekatronika SMK Negeri 4 Jakarta yang berlamatkan Jalan Jl.Rorotan, RT.4/RW.5 Rorotan, Cilincing, Kota Jakarta Utara, DKI Jakarta. . Waktu yang digunakan untuk melaksanakan penelitian yaitu pada bulan Oktober - Juli 2017 yang meliputi tahap perencanaan, penelitian, dan penulisan laporan.
Adapun Metode penelitian yang digunakan dalam penelitian menggunakan metode Research and Development. Menurut Sugiyono (2016: 297), Metode Research and Development atau penelitian pengembangan adalah metode penelitian yang digunakan untuk menghasilkan produk tertentu, dan menguji keefektifan produk tersebut. Metode pengembangan mengadaptasi dari model pengembangan ADDIE yang dikembangkan oleh Dick and Carry (1996) untuk merancang media pembelajaran. Model pengembangan yang terdiri dari lima tahap yang meliputi analisis (analysis), desain (design), pengembangan (development), implementasi (implementation), dan evaluasi (evaluation). Gambar 1 adalah flowchart rancangan penelitian.

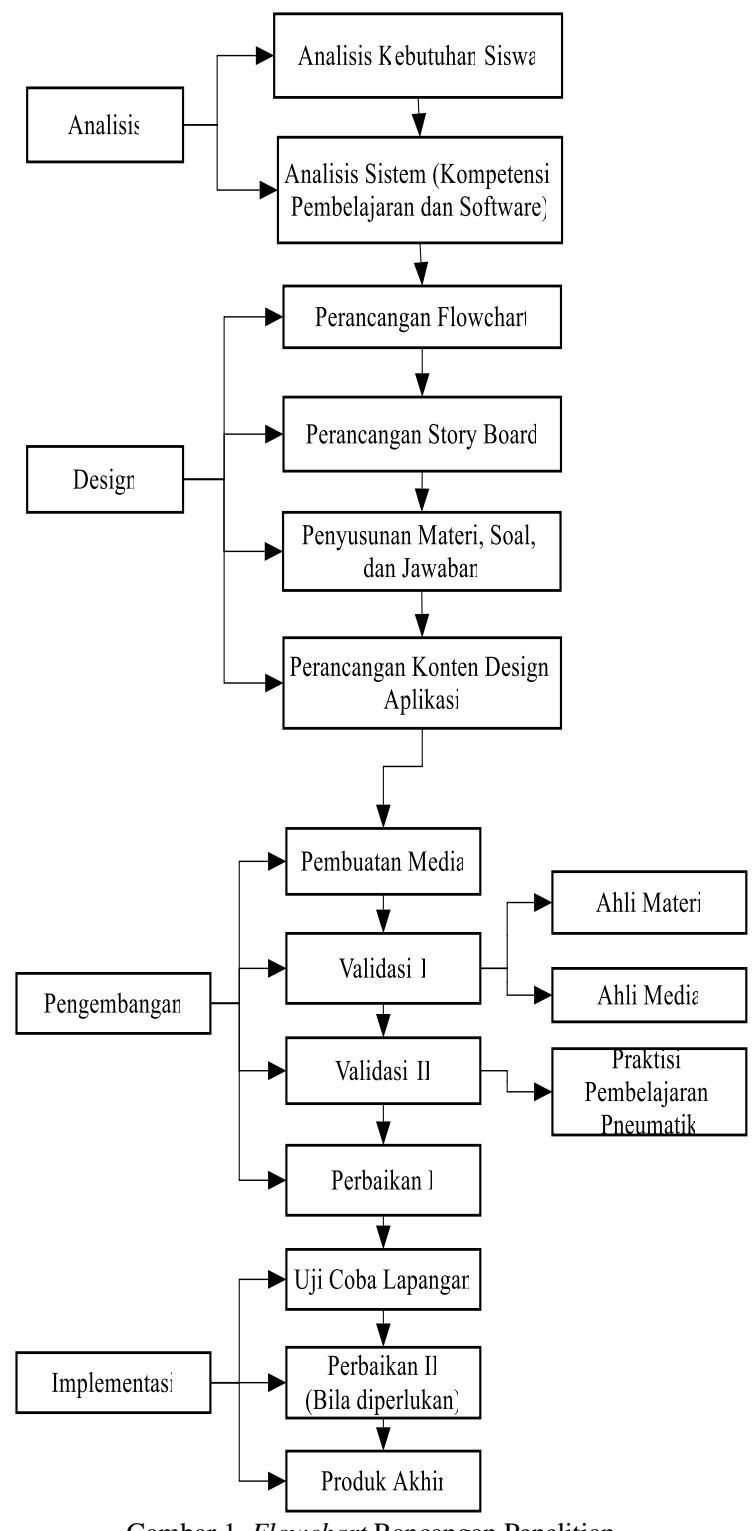

Gambar 1. Flowchart Rancangan Penelitian 
III. HASIL DAN PEMBAHASAN

A. Hasil Pengembangan Produk

1) Pembuatan Media

Tahap pembuatan media merupakan tahap realisasi dari perancangan flowchart dan storyboard, pada tahap ini media pembelajaran dibuat dengan menggunakan software Adobe Animate CC dengan Action Script 3.0. Gambar 2 adalah area kerja Adobe Animate CC.

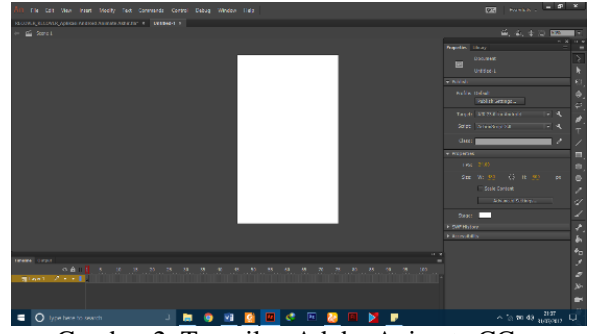

Gambar 2. Tampilan Adobe Animate CC

Langkah-Langkah

Pembuatan

Aplikasi dengan menggunakan Software Adobe Animate CC : Langkah awal yaitu dengan membuka lembar kerja Adobe Animate klink new pada window dan pilih Air for Android agar nantinya compatible ketika di instal dalam pada smartphone.

Mulailah mendisain aplikasi sesuai dengan konsep perancanagan yang telah dibuat sebelumnya pada lembar kerja yang telah dibuat, perguanaan tools-tools yang ada dipaling kanan untuk mendesain aplikasi., aplikasi dibuat dengan masing-masing bagian frame sesuai konten agar lebih memudahkan pengerjaan. Gambar 3 menunjukan tampilan pembuatan konten aplikasi pneumatik

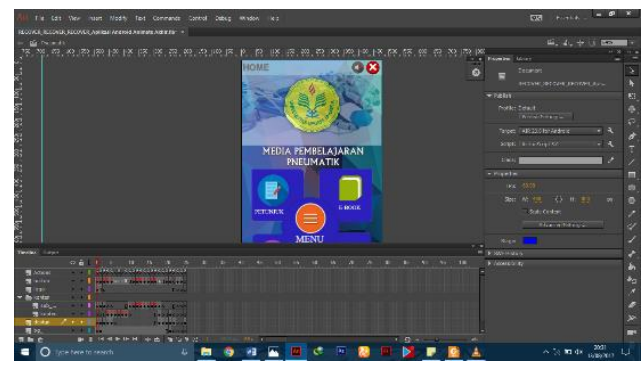

Gambar 3. Gambar Pembuatan Konten Aplikasi

Pada setiap frame yang terdapat konten kita harus menambahankan Script yang berfungsi sebagai program didalam aplikasi yang akan dibuat, script yang digunakan dalam adobe animate for android yaitu Action Script 3.0 yang sudah compatible dengan smartphone android. Gambar 4 menunjukan tampilan action script pada pembuatan aplikasi.

Setelah semua proses pembuatan aplikasi telah selesai dibuat maka lakukanlah proses simulasi yaitu untuk menguji apakah aplikasi yang telah dibuat bekerja dengan baik dan sudah sesuai perancangan. Gambar 5 menunjukan tampilan ketika melakukan simulasi.

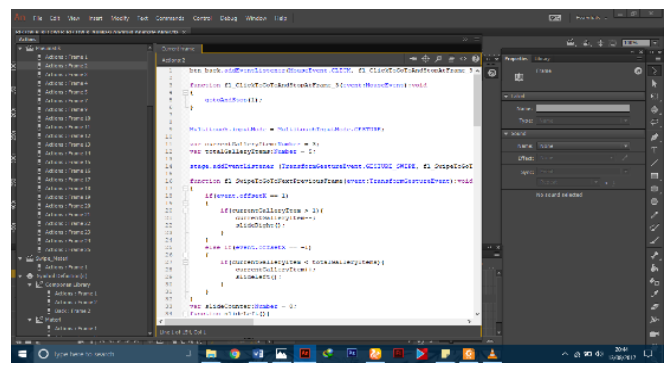

Gambar 4. Gambar Tampilan Action Script 3.0

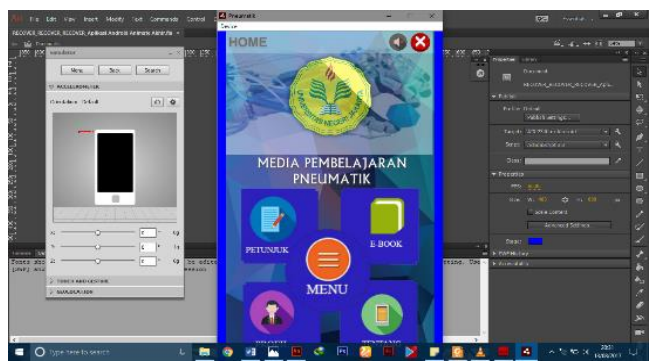

Gambar 5. Gambar Tampilan Simulasi

Proses terakhir dalam pembuatan aplikasi dengan menggunakan software adobe animate cc adalah yaitu dengan mengkonvert/mempublish ke dalam bentuk .apk yang nantinya dapat diinstal di smartphone android. Gambar 6 menunjukan tampilan publish ke dalam apk.

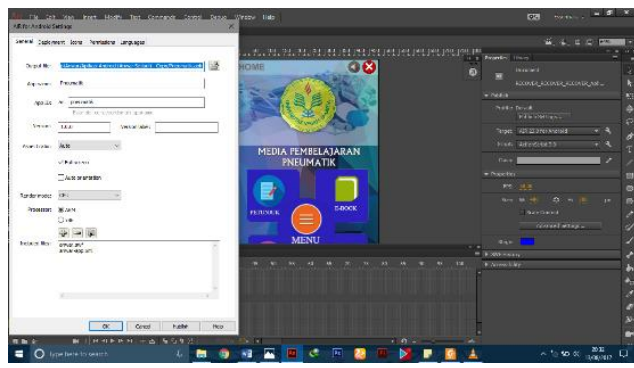

Gambar 6. Gambar Tampilan Tahap Mempublish Apk

Tahap pengujian pada smartphone dapat dijalan menggunakan proses debugging pada perangkat smartphone, pada penelitian ini tahap pengujian menggunakan smartphone Samsung Galaxy J5 dengan spesifikasi CPU: QuadCore, 1.2GHz Display: Super AMOLED, 720 x 1280 (HD), Camera Resolution: CMOS 13.0 MP, Versi Android 4.4 Kitkat. Pengujian dilakukan untuk mengetahui apakah fungsi-fungsi yang terdapat dalam aplikasi setelah proses coding dapat berjalan dengan benar dan untuk menemukan kekurangan atau kesalahan yang harus diperbaiki, jika dalam 
pengujian masih belum sesuai dan terdapat permasalahan maka akan dilakukan perbaikan baik terhadap objek maupun fungsi sebelum dilakukan nya proses Validasi.

\section{B. Hasil Penelitian}

Pada penelitian ini peneliti melakukan tahapan, yaitu melakukan pengambilan data menggunakan kuesioner (Angket).

\section{1) Validasi Ahli Materi}

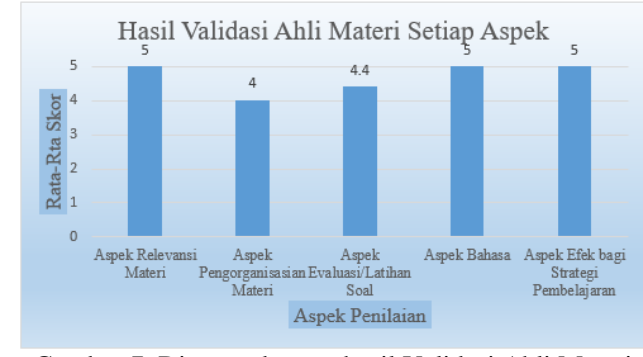

Gambar 7. Diagram batang hasil Validasi Ahli Materi

Berdasarkan Gambar 7 dapat disimpulkan bahwa penilaian media pembelajaran pneumatik berdasarkan seluruh aspek penilaian materi mendapatkan nilai rata-rata 4.55 dengan presentase nlai $90.91 \%$ yang berada pada kategori Sangat Layak digunakan sebagai multimedia pembelajaran intraktif.

\section{2) Validasi Ahli Media}

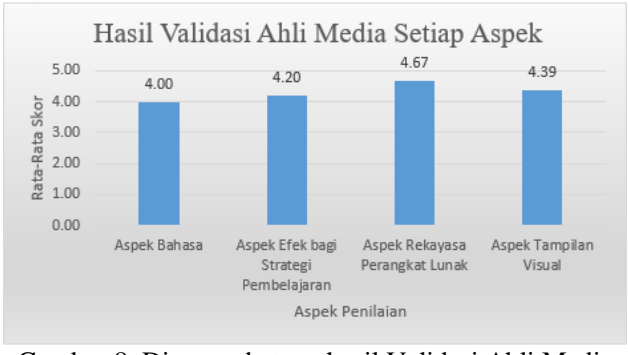

Gambar 8. Diagram batang hasil Validasi Ahli Media

Berdasarkan Gambar 8 dapat disimpulkan bahwa penilaian media pembelajaran pneumatik berdasarkan seluruh aspek penilaian media mendapatkan nilai rata-rata 4.31 dengan presentase nlai $86.25 \%$ yang berada pada kategori Sangat Layak digunakan sebagai multimedia pembelajaran intraktif

\section{3) Validasi Praktisi Pembelajaran}

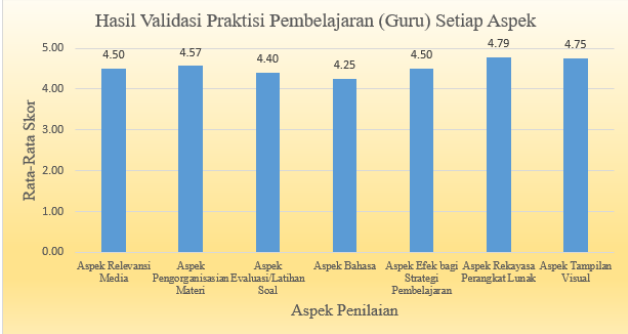

Gambar 9. Diagram batang hasil Validasi Praktisi Pembelajaran

Berdasarkan Gambar 9 dapat disimpulkan bahwa penilaian media pembelajaran pneumatik berdasarkan seluruh aspek penilaian media mendapatkan nilai rata-rata 4.31 dengan presentase nlai $86.25 \%$ yang berada pada kategori Sangat Layak digunakan sebagai multimedia pembelajaran intraktif.

4) Penilaian Siswa

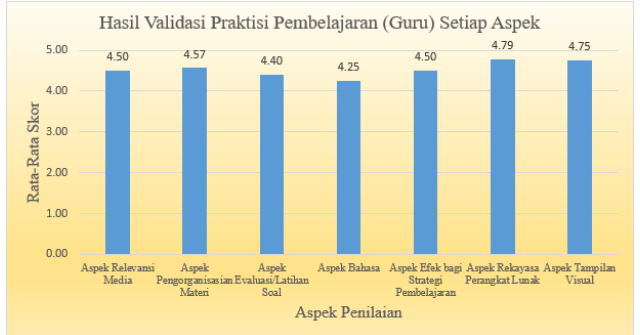

Gambar 10. Diagram batang hasil Penilaian Siswa

Berdasarkan Gambar 10 dapat diketahui bahwa rata-rata skor yang di dapatkan dari penilaian siswa terhadap media pembelajaran pneumatik yaitu $(X)=4.03$ yang berdasarkan tabel rentang penilaian berada pada 3,41 - 4,20 yang dapat dikategorikan Layak, dari hasil perhitungan menunjukan bahwa dari kualitas aspek materi dan penggunaannya berdasarkan aspek relevansi materi, aspek pengorganisasian materi, aspek evaluasi/latihan soal, aspek bahasa, aspek efek bagi strategi pembelajaran, aspek rekayasa perangkat lunak, dan aspek tampilan visual, media pembelajaran pneumatik yang telah dibuat Layak digunakan sebagai multimedia pembelajaran interaktif oleh siswa.

\section{KESIMPULAN}

Adapun kesimpulan hasil dari analisis penelitian yang penulis lakukan adalah sebagai berikut: 1) Pengembangan aplikasi android untuk pembelajaran pneumatic telah dikembangkan dengan menggunakan model pengembangan ADDIE yaitu melalui proses analisis (Analysis), desain (Design), pengembangan (Development), Implementasi (Implementation), dan evaluasi (Evaluation). Pada penelitian ini dibatasi hanya sampai tahap implementasi. 2) Tingkat kelayakan aplikasi android dapat dilihat dari hasil validasi ahli materi, ahli media, praktisi pembelajaran pneumatik, dan penilaian siswa. Penilaian kelayakan oleh ahli materi mendapatkan nilai ratarata 4.55 dengan persentase $90.91 \%$ dan termaksud dalam kategori Sangat Layak. Penilaian kelayakan oleh ahli media mendapatkan nilai rata-rata 4.31 dengan persentase $86.26 \%$ dan termaksud dalam kategori Sangat Layak. Penilaian kelayakan oleh praktisi pembelajaran pneumatik (guru) mendapatkan nilai rata-rata 4.54 dengan persentase $90.74 \%$ dan termaksud dalam kategori Sangat Layak. Pada tahap implementasi kepada siswa mumtimedia pembelajaran interaktif mendapatkan nilai rata-rata 4.03 dengan perssentase 80.53 dan termaksud dalam kategori Layak. 


\section{REFERENSI}

[1] Ade Wahyudi. (2015). Indonesia

Raksasa Teknologi Digital Asia,

Diaksesdari

https://www.tempo.co/read/kolom/2015/1

0/02/2310/indonesia-

raksasateknologidigital-asia\%20/, diakses pada tanggal 5 Maret 2017

[2] Anderson dan Krathwohl. 2002. Revisi

Taksonomi Bloom. Jakarta:

Rineka Cipta.

[3] Andi Prastowo. (2012). Panduan Kreatif Membuat Bahan Ajar Inovatif. Yogyakarta: Diva Press.

[4] Arif S. Sadiman, dkk. (1986). Media Pendidikan Pengertian, Pengembangan dan Pemanfaatannya. Jarkarta: CV Rajawali

[5] Azhar Arsyad (2013). Media

Pembelajaran. Jakarta: Rajawali Pers

[6] Daryanto. (2016). Media Pembelajaran. Yoryakarta: Penerbit Gava Media

[7] Dick and Carey. 1996. The Sistematic Design of Instruction. Fourth Edition: Harper Collins College Publisher.

[8] Direktorat Pembinaan Sekolah Menengah Atas. (2008). Panduan pengembangan bahan ajar. Jakarta: Departemen Pendidikan Nasional.

[9] Endang Mulyatiningsih. (2011). Metode Penelitian Terapan Bidang Pendidikan. Bandung: Alfabeta

[10] [FT] Fakultas Teknik. 2015. Panduan Penyusunan Skripsi, dan Non Skripsi. Jakarta: Fakultas Teknik, Universitas Negeri Jakarta

[11] Gian_D.O. (2015). Pengembangan Media Pembelajaran Berbasis Android dalam Bentuk Buku Saku Digital untuk Mata Pelajaran Akuntansi Kompetensi Dasar Membuat Ikhtisar Siklus Akuntansi Perusahaan Jasa di Kelas XI MAN 1 Yogyakarta Tahun Ajaran 2014/2015. [Skripsi].Yogyakarta: Fakultas Ekonomi, Universitas Negeri Yogyakarta

[12] Krist, T., dan Ginting, D. (1993). Dasar dasar Sistem Pneumatik. Erlangga. Jakarta.

[13] Luqman Arumanadi. (2014).

"Pengembangan Aplikasi Pocket Book of Physics (PBOP) Sebagai Media Pembelajaran Fisika SMA Kelas XI untuk Platform Android". [Skripsi] Yogyakarta, Universitas Negeri Yogyakarta
[14] Martinis Yamin. (2012). Desain Baru Pembelajaran Jakarta: Referensi.

[15] Mulianto, E. Suanli, dan T. Sutanto. (2002). Perancangan Sistem Pneumatik dengan Aplikasi pada Walking Robot. Universitas Bina Nusantara. Jakarta.

[16] Nuraini Razak, UNICEF Indonesia (2014). Kebanyakan Anak Indonesia sudah online, namun

masih banyak yang tidak menyadari potensi resikonya. https://www.unicef.org/indonesia/id/medi a 22169.html. diakses pada tanggal 5 Maret 2017.

[17] Nana Sudjana. (2009). Dasar-Dasar Proses Belajar Mengajar. Bandung: Sinar Baru Algensindo.

[18] Purbasari, Rohmi Julia, dkk. 2013.

Pengembangan Aplikasi Android sebagi Media Pembelajaran Matematika pada Materi Dimensi Tiga untuk Siswa SMA Kelas X.

[19] Putra, D.R. 2016. Pengembangan Game Educatif Berbasis Android Sebagai Media Pembelajaran Akutansi Di Kelas XI IPS SMA Negeri 1 Imogiri Pada Materi Jurnal Penyesuaian Perusahaan Jasa. [Skripsi] Yogyakarta, Fakultas Teknik, Universitas Negeri Yogyakarta

[20] Satyaputra dan Aritonang. (2014). Beginning Android Programming with ADT Budle. Jakarta: Elex Media Komputindo.

[21] Siregar.E dan Nara.H. (2014). Teori Belajar dan Pembelajaran. Bogor: Penerbit Ghalia Media

[22] Sukardjo. (2005). Evaluasi Pembelajaran Semester 2. Yogyakarta: PPs UNY

[23] Sugiyono. (2016). Metode Penelitian. Bandung: Alfabeta

[24] Weni Rinta Aryantari. (2014). Pengembangan Mobile Edukasi Berbasis Android Sebagai Media Pembelajaran Akuntansi Untuk Siswa Kelas XI IPS SMA. [Skripsi]. Yogyakarta: Fakultas Ekonomi, Universitas Negeri Yogyakarta.

[25] Wikipedia. Adobe Animate CC. https://en.wikipedia.org/wiki/Adobe_Ani mate. Diakses Pada Tanggal 9 April 2017

[26] Zuliana dan Irwan Padli. (2013). Aplikasi Pusat Panggilan Tindakan Kriminal di Kota Medan

Berbasis Android. Jurnal. IAIN Sumatra Utara Medan (Hal. 2-4) 